\title{
Standardization supporting future smart cities - a case of BIM/GIS and 3D cadastre
}

\author{
Karel Janečka ${ }^{1 \otimes}$ \\ ${ }^{1}$ Department of Geomatics, Faculty of Applied Sciences, University of West Bohemia, Czech Republic \\ \janecka@kgm.zcu.cz
}

\begin{abstract}
The aim of the paper is to give an overview of selected ongoing ISO standardization activities in the domain of geographic information dealing with BIM/GIS and 3D cadastre. The presented international standards have also a close relation to the activities (e.g. 3D spatial planning) from which the smart cities could benefit. In particular, in this paper the ISO 19152 Geographic information - Land Administration Domain Model (LADM) standard and ISO 19166 Geographic information - BIM to GIS conceptual mapping (B2GM) standard (still under development) are emphasized. Both mentioned standards are also strongly interrelated with each other. The ISO 19152 standard supports the smart registration of real estates by providing a conceptual schema incorporating 3D parcels, i.e. the 3D cadastre. 3D cadastre can provide the accurate, authoritative and unambiguous foundation for understanding the urban form. The second version of the ISO 19152 is also going to be extended to manage the spatial planning information. This enables 3D spatial planning in connection with the legal information, which is all together of big importance for building the smart cities. Furthermore, the ISO 19166 standard is going to provide a conceptual framework for transformation of BIM into GIS (at various level of details) and vice versa. This enables a wider use of existing detailed and semantically rich 3D digital BIM data in building of the 3D cadastre and smart cities GIS projects.
\end{abstract}

\section{Keywords}

3D cadastre, Land Administration Domain Model,

Geographic information

Received: 04 July 2019

Received in revised form: 18 September 2019

Accepted:

25 September 2019

\section{Highlights for public administration, management and planning:}

- There are currently two running projects within International Organization for Standardization (ISO) from which the smart city should benefit - the international standard ISO 19166 BIM2GIS and ISO TR 23262 GIS (geospatial) / BIM interoperability.

- There is an existing international standard ISO 19152 Land Administration Domain Model (LADM) supporting the creation of the 3D cadastre.

- The second version of the international standard ISO 19152, which is now under development, will bring a support for spatial planning and also the examples of technical encodings of LADM in BIM/IFC and CityGML.

\section{Introduction}

Among the key steps in the implementation of the smart city projects is creation of the 3D digital city model. These 3D models are of crucial importance for realization of smart city projects dealing with the third spatial dimension (elevation), e.g. urban and spatial planning, environmental simulations or disaster management. As argued by Shahrour (2018), geographical information system (GIS) is generally used for the construction of the digital model of urban 'horizontal components' such as urban networks, transport facilities and natural environment, while Building Information Modelling (BIM) is used for the description of 'vertical components' such as buildings. BIM is a process involving the generation and manage- 


\section{sciendo}
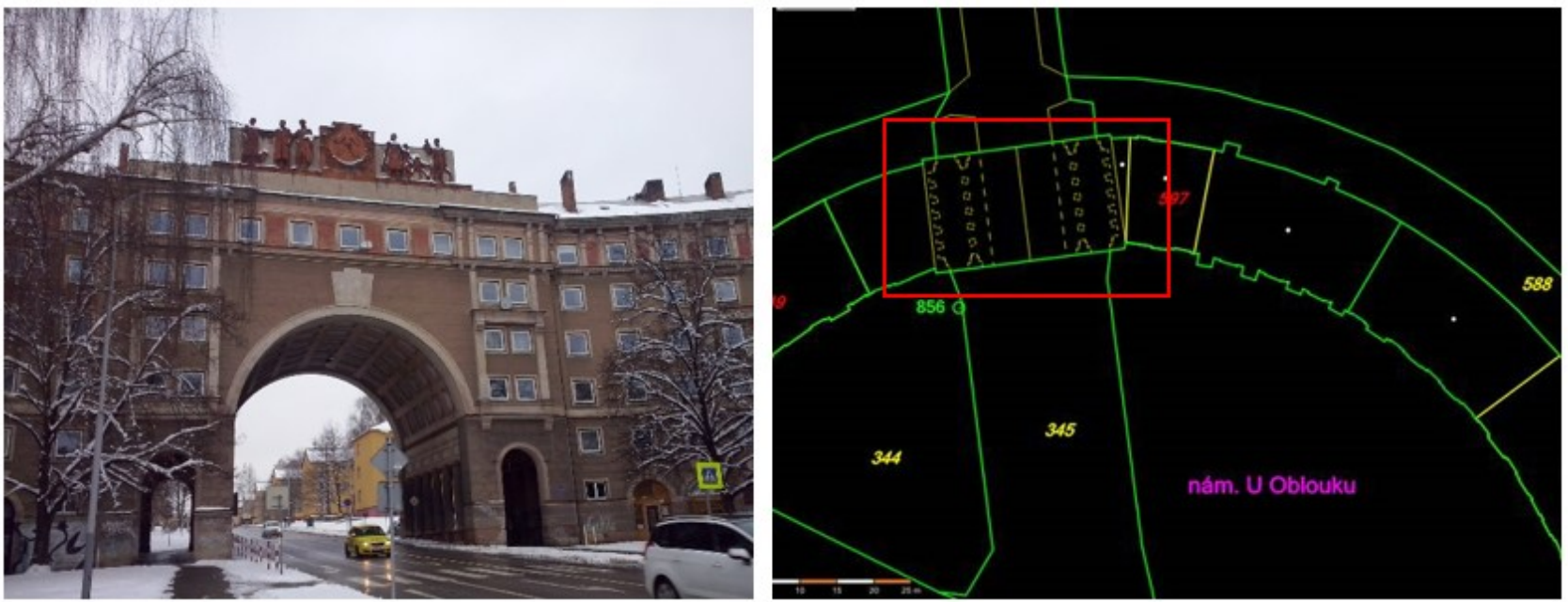

Fig. 1 Left - The building and the road going through this building. Right - 2D digital cadastral map. The building with the road is displayed in the red rectangle.

ment of digital representations of physical and functional characteristics of places. The 3D digital BIM models could serve well for the smart cities purposes, in terms of geometry and attributes. However, due to the various level of details requested by different smart city applications, their appropriate transformation into the GIS world has to be considered. Therefore, it is necessary to consider the related international standards which prescribe the way how to go from the BIM world into the GIS domain.

Furthermore, due to the demography trends, i.e. the density of population especially in cities is rapidly growing and the prize of real estates (e.g. building apartments) is growing even more, a change of used 2D parcel paradigm as a base of cadastral registration should be considered. Rajabifard and Ho (2015) argue that 2Dbased paradigm in recording and representing land and property information is of limited utility, and that there is clear demand for more efficient approaches to information management and analysis for decision-making with location (3D land and property). This is essential to achieving sustainable planning outcomes and ongoing management of smart cities. As presented by Kitsakis et al. (2018), the 3D real estates like building apartments are registered in most of countries but it is nearly impossible to display them on the used 2D digital (cadastral) map. The change of 2D parcel paradigm towards registration of 3D spatial units (3D parcels) would enable to register and display also these 3D real estates. The connection of 3D cadastral information with the multiple information streams pertaining to the urban built environment preserves the relevancy and role of cadastral information as fundamental to all societies (Rajabifard 2014). The Fig. 1 displays the building with apartment units and the road going through the building. In 2D digital cadastral map it is not possible to display the spatial boundaries of all spatial units. As the cities are becoming structurally complex with also rising underground infrastructure, the 3D cadastre provides a smart response.

An umbrella organization for standardization activities in the field of digital geographic information is International Organization for Standardization (ISO) and its technical committee 211 Geographic information/Geomatics (ISO/TC 211). The work of ISO/TC 211 aims to establish a structured set of standards for information concerning objects or phenomena that are directly or indirectly associated with a location relative to the Earth. The developed standards should provide a framework for the development of sector-specific applications using geographic data.

The aim of the paper is to give an overview of selected ongoing ISO standardization activities in the domain of geographic information dealing with BIM/GIS and 3D cadastre. The presented international standards have also a close relation to the activities (e.g. 3D spatial planning) from which the smart cities could benefit. In particular, in this paper the ISO 19152 Geographic information - Land Administration Domain Model (LADM) standard and ISO 19166 Geographic information BIM to GIS conceptual mapping (B2GM) standard (still under development) are emphasized. Both 
mentioned standards are also strongly interrelated with each other. The ISO 19152 standard supports the smart registration of real estates by providing a conceptual schema incorporating 3D parcels, i.e. the 3D cadastre. 3D cadastre can provide the accurate, authoritative and unambiguous foundation for understanding the urban form (Rajabifard 2014).

The interoperability should be considered within the spatial planning and land administration processes in order to ensure the effectiveness of spatial planning documents. As the second version of the ISO 19152 LADM is going to be extended to manage the spatial planning information, it implies an integration of spatial planning and land administration environments. The re-use of defined zones from spatial planning into restrictions to land rights is supported by the revised version of ISO 19152. The extension of the scope of ISO 19152 will enable a 3D spatial planning in connection with the legal (cadastral) information as explored by Bydłosz et al. (2018), which is in combination with BIM of big importance for building the smart cities. Van Berlo et al. (2017) proposed the usage of BIM and 3D spatial planning data for the automatic building permission. As defined by Ridel (2004), the planning is an effort to improve the communities and natural environments that balances socio-economic-environmental outcomes. Decision-making by local government on land utilizes maps to impose a spatial plan in rights, restrictions and responsibilities. Furthermore, the ISO standard 19166 and ISO technical report 23262 are going to provide a conceptual framework for transformation of BIM into GIS (at various level of details) and vice versa. This enables a wider use of existing detailed and semantically rich 3D digital BIM data in building of the 3D cadastre and smart cities GIS projects. Such approach could be also important for preservation of the culture heritage (Coruhlu et al., 2016).

The rest of the paper is structured as follows: section 2 introduces the main characteristics of the ISO 19152 international standard and emphasizes the fact that this standard enables registration of real estates represented by related 3D geometries. Section 3 is dedicated to the ongoing revision of the ISO 19152 standard with focus towards 3D spatial planning and re-using of existing BIM/IFC data for 3D cadastre purposes. The ongoing ISO standardization activities related to the conversion between BIM and GIS are described in section 4 and section 5 . The paper ends with conclusions given in section 6 .

\section{Land Administration Domain Model as a base for 3D cadastre}

The first edition of the international standard ISO 19152:2012 Geographic information - Land Administration Domain Model (ISO/TC 211, 2012) was published in 2012. It defines a reference conceptual model covering basic information-related components of land administration (including those over water and land, and elements above and below the surface of the earth). The first edition of the standard consists of three packages (Party, Administrative and Spatial Unit) and one subpackage (Surveying and Representation). A (sub)package is a group of classes, with a certain degree of cohesion. The four main classes of the ISO 19152 standard are (ISO/TC 211, 2012):

1. Class LA Party. Instances of this class are parties. The party is a person or organization that plays a role in a rights transaction. An example of the organization may be a company, a municipality or the state.

2. Class LA_RRR. Instances of subclasses of LA RRR are rights, restrictions or responsibilities. The right is an action, activity or class of actions that a system participant may perform on or using an associated resource. The restriction is a formal or informal obligation to refrain from doing something. The responsibility is a formal or informal obligation to do something.

3. Class LA_BAUnit. Instances of this class are basic administrative units. The basic administrative unit is an administrative entity, subject to registration (by law), or recordation, consisting of zero or more spatial units against which (one or more) unique and homogeneous rights, responsibilities or restrictions are associated to the whole entity, as included in a land administration system.

4. Class LA_SpatialUnit. Instances of this class are spatial units (including 3D spatial units). The spatial unit is a single area (or multiple areas) of land and/or water, or a single volume (or multiple volumes) of space.

ISO 19152 defines 3D spatial unit as single volume (or multiple volumes) of space. The boundary of 3D spatial unit is formed by boundary faces. Spatial units are structured in a way to support the creation and management of basic administrative units. 


\section{D cadastre}

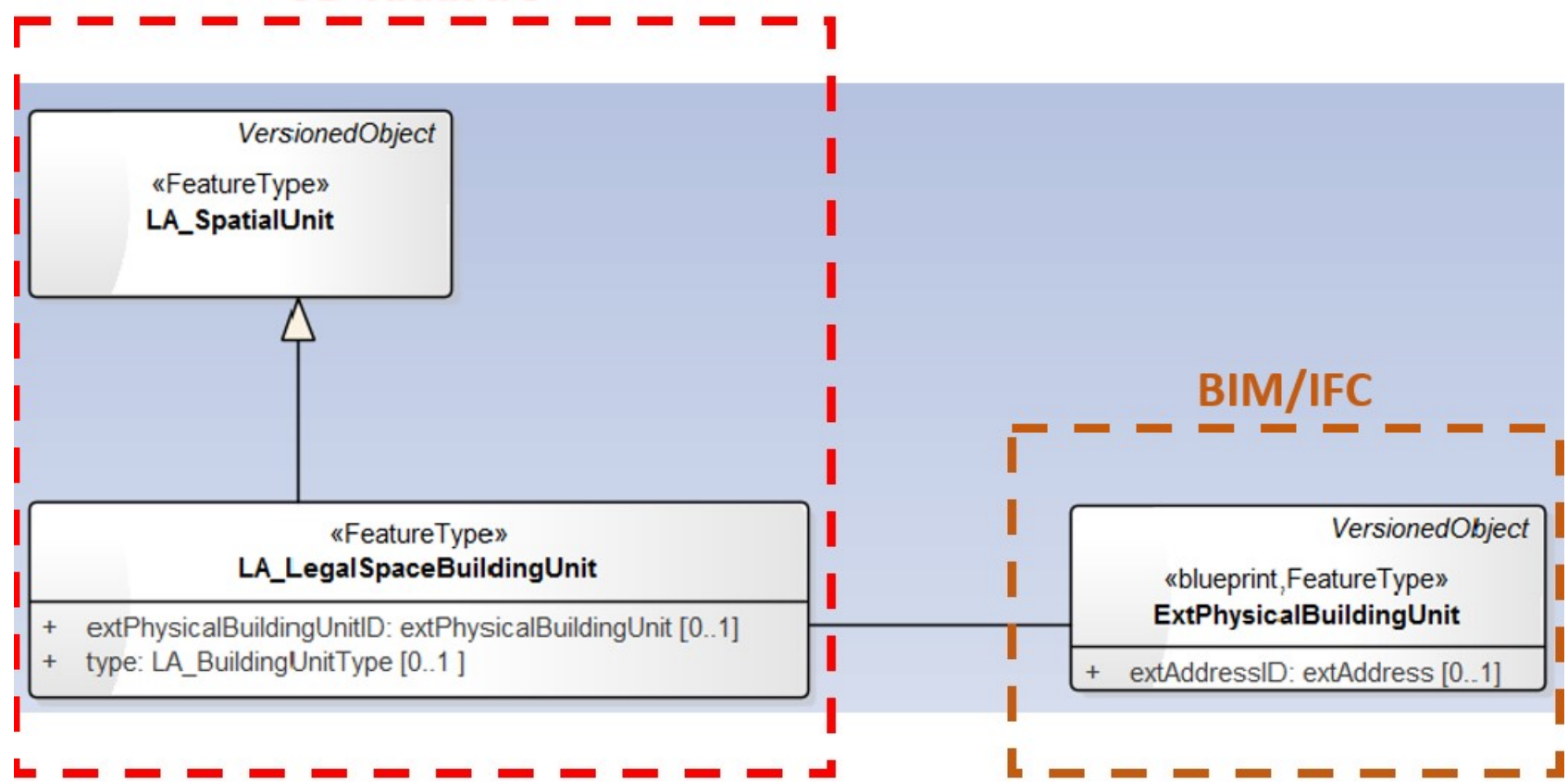

Fig. 2 ExtPhysicalBuildingUnit is a class for the external registration of mapping data of building units. Source: modified according to (ISO/TC 211 2012)

The basic administrative units are subjects to registration (by law) against which unique and homogeneous rights (or restrictions/responsibilities) are associated. Spatial units can be further specialized into building units or utility networks. ISO 19152 also provides stereotype classes for the data sets from the external sources. From this perspective, the first version of ISO 19152 published in 2012 supports the idea of reusing of the existing 3D external data (e.g. BIM) for 3D cadastre purposes (Fig. 2). The second version of ISO 19152, which is currently under development, goes a step further (in terms of described detail) and should provide users with examples of LADM technical encodings (e.g. using $\mathrm{BIM} / \mathrm{IFC})$.

\section{Land administration domain model Revisions and support of 3D spatial planning}

In 2018, ISO/TC 211 approved to revise the ISO 19152 standard. At initiate stage 0 all requirements from a diverse group of organizations are gathering. Urban managers and planners could benefit tremendously from 3D digital city models. This is especially true in light of the rapid urbanization worldwide, which requires continuous monitoring of en- ergy consumption, noise pollution and many other smart city applications. Enriching 3D city models with non-spatial information supports urban planning and establishment and maintenance of 3D cadastres based on registration of 3D parcels (3D spatial units). Such enrichment requires the realisation of a scalable system able to store, manipulate, analyse, manage and visualise different types of spatial and non-spatial data and their interrelationships (Toschi et al. 2017).

During the $47^{\text {th }}$ ISO meeting week in Wuhan in November 2018 a scope of the revised ISO 19152 standard was agreed. The new version of the ISO 19152 is going to be significantly extended for new packages and annexes. Newly, the ISO 19152 considers also the spatial planning information. As argued by Indrajit et al. (2018), an integration of legal and spatial planning information is needed. For example, spatial planning regulates total height of a building on a parcel. The importance of urban form in smart cities and 3D spatial planning was also emphasized by the researchers (Akaraci et al. 2016; Bydłosz et al. 2018). In particular, the ISO 19152 package dedicated to spatial planning information supports geometry object which represent spatial planning hierarchy and geometric characteristics, facilitates information in spatial planning zoning and describes communities and their role in spatial planning. 
Legal spaces and legal objects have their own geometries which in many cases are not aligned with physical spaces and physical objects. The legal space should be linked to physical object. BIM/IFC or CityGML (OGC, 2012) offer options in this respect and therefore the revised version of ISO 19152 should contain the examples of LADM technical encodings in BIM/IFC and CityGML respectively. A link between BIM and land administration is important in relation to spatial planning and the whole lifecycle of the building..

\section{Building Information Modelling to GIS mapping}

Building Information Modelling (ISO 19166 BIM2GIS) is going to provide the conceptual framework for BIM to GIS information mapping and required mapping mechanisms. The conceptual framework for mapping BIM information to GIS is defined with the following three mechanisms:

1. BIM to GIS Perspective Definition (B2G PD): supports perspective information representation depending on the specific requirement such as the urban facility management. Perspective depends on the use-case.
For example, to manage the urban facilities, the required data should be collected from the various data sources including BIM model and transformed to represent in userspecific perspective. Perspective Definition defines a Data View to extract the needed data and transform the information from the various data sources.

2. BIM to GIS Element Mapping (B2G EM): supports the element mapping from the BIM model to the GIS model. As the BIM and GIS model schemas are different, B2G EM requires a mapping rule specifying how to transform from the BIM model to the GIS model element.

3. BIM to GIS LOD Mapping (B2G LM): supports LOD definitions and generation from the BIM model to the GIS model. LOD as defined in a GIS model consists of LODs representing the geometry information depending on an object in the GIS. The LOD models defined a visualization mechanism and classes which are like a boundary representation based on a surface concept. However, there are no LOD objects in BIM objects as defined in ISO 16739:2013 Industry Foundation Classes (IFC) for data sharing in the construction and facility management industries.
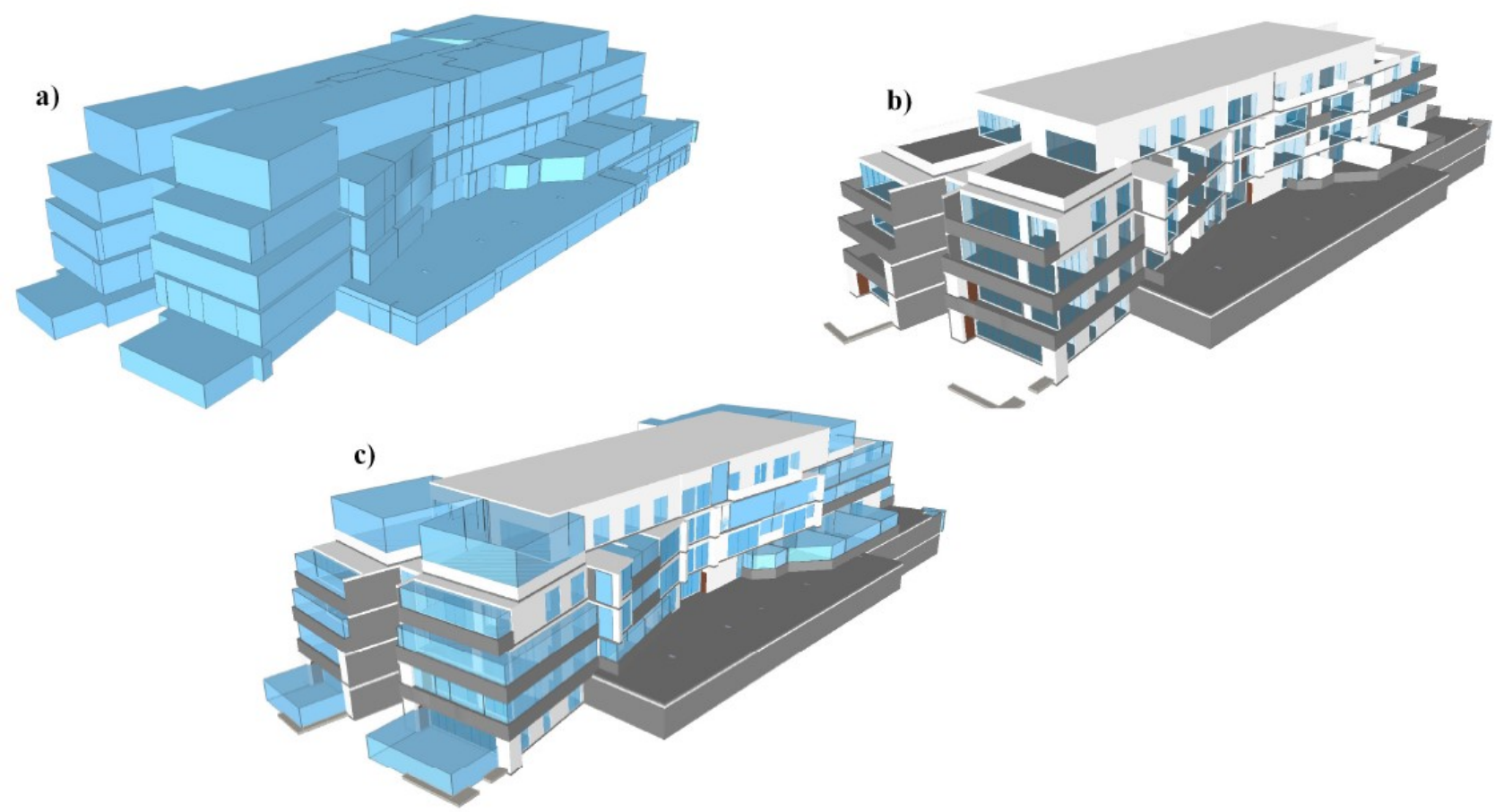

Fig. 3 Three types of building models based on BIM. (a) Pure legal model. (b) Pure physical model. (c) Integrated model. Source: (Atazadeh et al. 2016) 

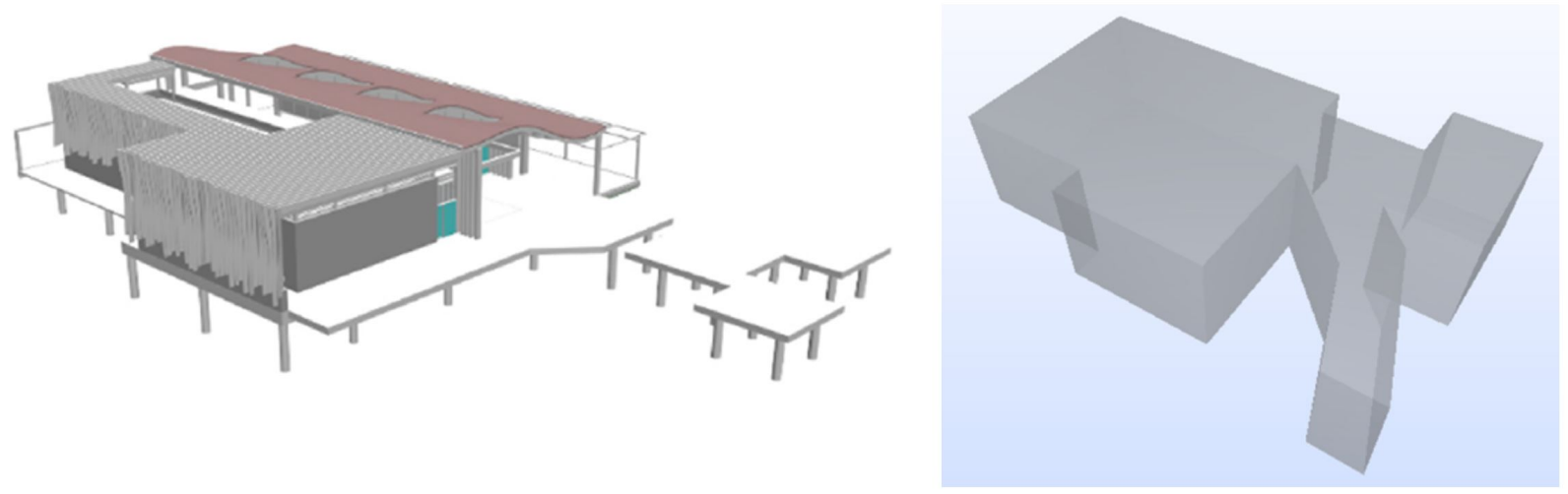

Fig. 4 Left - IFC model of the Lakeside restaurant. Right - Corresponding Conceptual Mass as an IFCSpace object. The whole restaurant has been redrawn as a closed volume. Source: (Oldfield et al. 2017)

To represent a BIM object in the GIS, LOD information needs to be extracted from the BIM model considering each LOD concept of GIS model. This can be defined by the LOD mapping rule set

As national governments around the world begin to mandate the use of BIM, it certainly underscores the rationale of exploring BIM for cadastral purposes (Rajabifard 2014). The first attempts in using BIM/IFC data as a source for 3D cadastre have been explored and presented (van Oosterom et al. (2014), Oldfield et al. (2016), Atazadeh et al. (2017)) as the registration based on 3D parcels is of high importance for modern smart societies. It should be noted, that ISO 19152:2012 focuses on legal spaces rather than on physical spaces, though in some specific instances, both may well happen to have same extent (Dimopoulou et al. 2018). The legal space is often an envelope of around the physical space but protrusions are sometimes allowed. Atazadeh et al. (2016) constructed three types of BIM models for multilevel building. One of these models is a pure legal BIM model of the building suitable for 3D cadastre purposes (Fig. 3). This approach uses legal spaces to represent 3D cadastral objects. The next model is based on physically existent building elements such as walls, doors etc. The last one (an integrated model), comprising both legal and physical spaces, can help the final user to better understand the scope of legal spaces.

Oldfield et al. (2017) proposed a mapping between the BIM/IFC and the ISO 19152 (LADM) (Fig. 4) to demonstrate a usability of BIM data for 3D cadastres purposes based on Model View Definition (MVD) with aim to stay within the resources of the IFC's common schema and not try to extend the model further. As the IFC standard contains several hundreds of elements, the usage of MVD leads to definition of a subset of a model before mapping.

\section{Towards interoperability between BIM and GIS}

A closely related work to the ISO 19166 (B2GM) is the technical report ISO/NP TR 23262 GIS (GEOSPATIAL) / BIM INTEROPERABILITY. This technical report aims to identify the standards requirements to enable a two-way mapping between the two platforms, allowing any BIM/IFC model to be mapped to GIS application schemas, and the opposite way around. The technical report ISO/TR 23262 is going to study:

1. Development of mapping and rules for semantic mediation of information flow between GIS (General Feature Model as defined in ISO 19101:2014 Geographic information - Reference model and ISO 19109:2015 Geographic information - Rules for application schema) and IFC metamodel, both directions.

2. Mapping between GIS geometry/topology model (ISO 19107:2003 Geographic information - Spatial schema) and ISO 10303-42:2014 Industrial automation systems and integration - Product data representation and exchange - Part 42: Integrated generic resource: Geometric and topological representation. It will explore geometric and topological representation, including differences in segment types and interpolations of curves and surfaces. 
3. Transformation between GIS and BIM coordinates. GIS has a scale factor in their projections, which may give deviations when it comes to high precision data and BIM uses 3D Cartesian coordinates that may give deviations when it comes to special data as it treats the world as a flat surface.

4. The relationship between feature types in GIS and logical coupling of elements in IFC, and further semantic interoperability.

5. Mapping of terms between GIS and BIM.

6. Recommendations from the Integrated Digital Built Environment Working Group (IDBE WG). The vision of this joint working group will be explained together conceptual differences between geospatial and BIM methodologies and a number of value chains for integrated digital built environment data and technologies.

\section{Conclusions}

The paper highlighted the selected ongoing international standardization activities with focus on 3D cadastre and BIM, and illustrated their connection with smart cities. Due to the technological developments the 3D geospatial data are becoming increasingly available. The 3D land and property ownership information can serve for effective planning of healthy and productive smart cities. This requires the change of the almost used 2Dbased paradigm in recording and representing land and property information towards registration of 3D spatial units. These 3D spatial units then can be used for representation of the underground constructions or the building units. The 3D BIM models potentially can serve well as an important and detail source of data for such 3D spatial units. With rising prizes of real estates, the owners want to see the spatial extent of their properties, however, the current maps are not able to satisfy this need. The ISO 19152 international standard, which is currently under revision and is going to be significantly extended, gives a conceptual base for building of the 3D cadastre based on registration of 3D spatial units. To enable wider usage of BIM data in the GIS projects dealing with smart cities, the transforming mechanisms are needed. The ISO 19166 standard (now at CD stage) should provide the professionals with a conceptual framework for doing such transformations. Furthermore, the scope of the ISO/NP TR 23262 GIS (Geospatial)
/ BIM interoperability technical report is to investigate barriers and propose measures to improve interoperability between geospatial standards developed by ISO/TC 211 and BIM standards developed by ISO/TC 59 SC 13 . There are still challenges to be further investigated and solved, especially a common terminology or a lack of experts having the deep knowledge of both domains. However, interoperability between BIM and GIS can create strong synergy effects at operational and strategic levels.

\section{References}

Akaraci S, Usman M A, Usman M R, Ahn D J (2016) From Smart to Smarter Cities: Bridging the Dimensions of Technology and Urban Planning. IEEE 2016 International Conference on Smart Green Technology in Electrical and Information Systems, Bali.

Atazadeh B, Kalantari M, Rajabifard A (2016) Comparing Three Types of BIM based Models for Managing 3D Ownership Interests in Multi-level Buildings. 5th International FIG 3D Cadastre Workshop, Athens.

Atazadeh B, Kalantari M, Rajabifard A, Ho S, Ngo T (2017) Building information modelling for high-rise land administration. Transactions in GIS 21 (1): 91-113.

Bydłosz J, Bieda A, Parzych P (2018) The Implementation of Spatial Planning Objects in a 3D Cadastral Model. International Journal of Geo-Information 7(4), 153.

Coruhlu Y E, Demir O, Yildiz O, Cete M (2016) The relation between structured cultural heritages and condominium towards 3D cadastre. Survey Review 48(351): 438-449.

Dimopoulou E, Karki S, Roić M, Duarte de Almeida J P, GriffithCharles Ch, Thompson R, Ying S, Paasch J, van Oosterom P (2018) Initial Registration of 3D Parcels. In: van Oosterom P (Ed.), Best Practices 3D Cadastres, pp. 67-94.

Indrajit A, Ploeger H, van Loenen B, van Oosterom P (2018) Designing Open Spatial Information Infrastructure to Support 3D Urban Planning in Jakarta Smart City. 6th International FIG 3D Cadastre Workshop, Delft.

ISO/TC 211 (2012) ISO 19152:2012 Geographic information Land Administration Domain Model, Geneva.

Kitsakis D, Paasch J, Paulsson J, Navratil G, Vucic N, Karabin M, El-Mekawy M, Koeva M, Janecka K, Erba D, Alberdi R, Kalantari M, Yang Z, Pouliot J, Roy F, Montero M, Alvarado A, Karki S (2018) Legal foundations. In: van Oosterom P (Ed.), Best Practices 3D Cadastres, pp. 1-66.

Oldfield J, van Oosterom P, Quak W, van der Veen J, Beetz J (2016) Can Data from BIMs by Used as Input for a 3D Cadastre? 5th International FIG 3D Cadastre Workshop, Athens.

Oldfield J, van Oosterom P, Beetz J, Krijnen F T (2017) Working with Open BIM Standards to Source Legal Spaces for a 3D Cadastre. International Journal of Geo-Information 6(11), 351.

Open Geospatial Consortium (OGC) (2012) OGC City Geography Markup Language (CityGML) Encoding Standard.

Ridell R (2004) Sustainable Urban Planning: Tipping the Balance. Wiley-Blackwell.

Shahrour I (2018) Use of GIS in Smart City Projects. Managing and Visualising Geospatial Data in a User-friendly Environment. 


\section{S sciendo}

Available from: <https://www.gim-international.com/content/article/use-of-gis-in-smart-city-projects>

Rajabifard A (2014) 3D Cadastres and Beyond. 4th International FIG 3D Cadastre Workshop, Dubai.

Rajabifard A, Ho S (2015) Towards smart future cities: 3D cadastres as a fundamental enabler. Coordinates. Available from: <https://mycoordinates.org/towards-smart-future-cities3d-cadastres-as-a-fundamental-enabler>

Toschi I, Nocerino E, Remondino F (2017) Geomatics Makes Smart Cities a Reality. Available from: <https://www.gim- international.com/magazines/gim-international-october2017.pdf>

van Berlo L, Dijkmans T, Stoter J (2013) Experiment for integrating Dutch 3D spatial planning and BIM for checking building permits. ISPRS 8th 3DGeoInfo Conference \& WG II/2 Workshop, Istanbul.

van Oosterom P, Stoter J, Ploeger H, Lemmen C, Thompson R, Karki S (2014) Initial Analysis of the Second FIG 3D Cadastres Questionnaire: Status in 2014 and Expectations for 2018. The 4th International Workshop on 3D Cadastres, Dubai. 